\title{
10
}

\section{Assisted voluntary return and reintegration of migrants: A comparative approach}

\section{Khalid Koser and Katie Kuschminder}

Sustainable voluntary return of migrants back to their origin countries is an important aspect of comprehensive migration management. It is widely recognised as the preferred mode of return and its take-up is a key issue in return management. It should ensure that the rights and dignity of the migrants involved are respected.

Both origin and destination countries support a wide range of policies and programs intended to facilitate sustainable voluntary return. Program criteria and conditions vary significantly, and it is not clear which settings are the most effective in enabling return, or promoting sustainable return and reintegration. A lack of accessible data and consensus on how to define and measure program effectiveness makes it more difficult to assess the impact of assisted voluntary return (Paasche, 2014). Program impact also varies across different types of migrants.

This chapter presents a summary of the findings of a comparative study that explored the factors influencing the decision to return, including the role played by return policy interventions. The study also aimed to 
enhance understanding of the concept of sustainable return, how to measure it, and how to promote it. The full report of the study is available on the International Organization for Migration (IOM) website. ${ }^{1}$

The overall aim of this research is to inform policies and programs for assisting the voluntary return and reintegration of migrants, including irregular migrants and unsuccessful asylum seekers. Three specific objectives support this aim: analysis of the migrant return decision; development of a framework for defining and measuring sustainable return; and an assessment of what factors determine reintegration and sustainable return.

This chapter is in five main sections. The next section summarises the methodological approach. The following section considers the factors influencing the decision to return, further testing a model developed in an earlier study. The third main section develops a new definition of 'sustainable return', and a return and reintegration index, which is subsequently tested. We then consider the factors that promote reintegration and sustainable return. The final section summarises the key policy implications arising from the study, with appropriate warnings concerning wider applicability.

\section{Methodology}

This study included three primary sources of data collection. First, a comprehensive literature and policy review was conducted on assisted voluntary return and reintegration and sustainable return. Second, an analysis was conducted of data on returns from the various destination countries, and of IOM-assisted voluntary return data for the selected origin countries. Finally, primary data were collected through interviews with migrants and returnees in destination, transit and origin countries, as well as with key stakeholders wherever possible to gain further information on the context of assisted voluntary return. This chapter mainly draws on this primary data.

Research was conducted in four destination countries (Australia, the Netherlands, Switzerland and the UK), eight origin countries (Afghanistan, Bangladesh, Ethiopia, Iraq, Pakistan, Sri Lanka, Sudan and

1 For the full report, see Koser and Kuschminder (2015). 
Vietnam) and three transit countries (Indonesia, Greece and Turkey). These study countries were selected in consultation with the Department of Immigration and Border Protection and IOM, and for various reasons, including their relevance in terms of priority migration flows to Australia, the scale of asylum and return flows, and the variety of assistance policies and programs.

A semi-structured interview questionnaire was used with migrants and returnees. A separate questionnaire was used in the origin countries and destination countries, and a slightly modified version of the destination country questionnaire was used in the transit countries. All of the questionnaires followed a life-cycle approach and, wherever possible, had the same questions to ensure comparability.

Recruitment of participants depended on the country context. In each destination country, the Department assisted the research team by seeking the cooperation of the appropriate government authority. Through this participation, the government in each destination country connected the research team with appropriate individuals or organisations for arranging and completing interviews. In each country, this worked slightly differently. In the origin countries, all participants were recruited by the IOM, and the vast majority of interviews took place at the IOM office. For the transit countries, as a result of each country's unique context, participants were selected in different ways. In Indonesia, all participants were refugees or asylum seekers living in IOM-provided accommodation in various locations in Jakarta, and the interviews were arranged by the IOM. In Turkey, the majority of interviews took place at a removal centre in Istanbul, and the remainder at the IOM office. In Greece, the majority of interviews took place at the IOM office in Athens.

\section{Understanding the decision to return}

The model shown in Figure 10.1 was used in this study for the purposes of research design and subsequent analysis of the return decision-making process, and was developed in an earlier study by Black et al. (2004). It conceives the individual return decision as being influenced by: 'structural' conditions (conditions in the origin and destination country); individual conditions including individual attributes and social relations; 
and policy interventions. The model also recognises the significance of information about conditions in origin and transit countries, and about policies, which may vary significantly between individuals and groups.

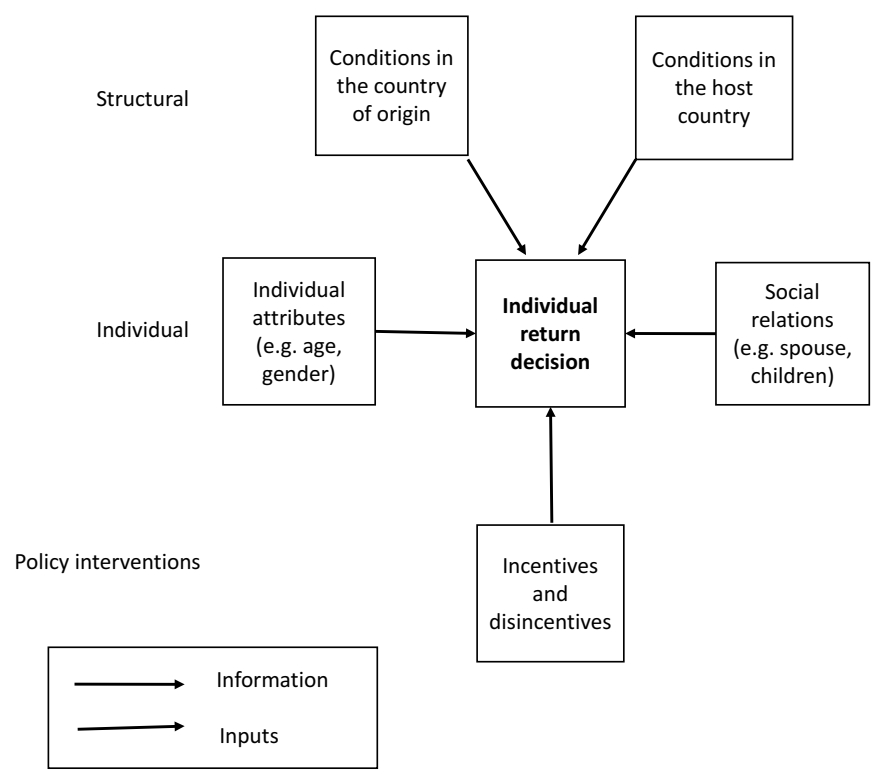

Figure 10.1: Factors determining the decision to return Source: Black et al. (2004), p.13.

\section{Conditions in the country of origin}

As very few respondents in any origin, transit or destination country identified conditions in the origin country as influential in their decision whether to return, the total number of responses is very small, and not suitable for detailed analysis. There was only one item within the broad category of conditions in the origin country not cited as relevant by any respondent at all, and that was a sense of political commitment or desire to help rebuild the country of origin.

\section{Conditions in the country of destination}

Across all the respondents, conditions in the destination country significantly outweighed any others as factors identified as influencing the return decision. For 80 respondents across all the countries surveyed (almost 30 per cent of the respondents), not having the right to work or 
experiencing difficulty in finding employment was cited as important. The second most cited (by 40 respondents or 14.7 per cent) was a negative decision on an asylum request. Ranked sequentially after employment and asylum status were financial factors (35 individuals or 12.8 per cent); a lack of security and discrimination (14 individuals or 5.1 per cent); the expiry of a work or student permit (10 individuals or 3.7 per cent); a lack of access to social services (seven individuals or 2.6 per cent); and that the respondent was 'tired of being in a detention centre' (four individuals or 1.5 per cent).

Given the prevailing discourse in many migrant destination countries that access to social services is an important magnet for asylum seekers and other migrants, it is interesting that no respondent interviewed in any destination country cited lack of access to these services as a factor influencing their return decision. It is not clear from the data whether this was not much of an issue because most respondents legally had access to social services, had found alternative access, or simply had not required these services by the time of the survey, but the conclusion stands that, for the vast majority, access to social services was not apparently a 'make or break' issue in considering whether or not to stay in the destination country.

\section{Individual factors}

Of the five categories identified in Figure 10.1 (conditions in origin countries, conditions in destination countries, individual factors, social factors and policy interventions), individual factors were the second most cited category influencing the return decision, by just over one third of respondents. Of the specific variables covered within this category, of most concern was that people were 'tired of living as undocumented', followed by 'I felt I had no other choice', 'inability to meet migration aspirations', 'psychological problems', and the importance of 'dignity of return as a normal passenger'.

This last variable was only cited by a total of three respondents. Yet it is often assumed that one of the reasons rejected asylum seekers and irregular migrants subscribe to organised return programs is to avoid the indignity (and potential subsequent reintegration challenges) of deportation. 
The data on age show no obvious trends. The majority in each age category in both transit and destination countries had decided to return, with the exception of people aged $40+$ in transit countries (of whom five had decided to return and eight not to). Turning to data on sex, this study covered significantly more men than women. Of the 42 men interviewed in destination countries, 64 per cent had decided to return, 19 per cent had decided not to return, and 17 per cent were undecided. Among the 11 women interviewed, six had decided to return, three had decided not to return, and two were undecided. In transit countries, overall almost twice as many participants had decided to return as the number who had decided not to return. However, more women had decided not to return than to return.

No clear patterns emerged concerning marital status. In both destination and transit countries, more respondents, both married and unmarried, had decided to return rather than not to return, although the differentials varied quite widely (for example, in transit countries almost as many married people had decided not to return as the number of married people who had decided to return). There is also no clear pattern when it comes to children. In both transit and destination countries more people, whether or not they had children, had decided to return than those who had decided not to return.

The correlations between return intentions and whether or not the respondent migrated alone are more interesting. The significant majority of those who had migrated alone to destination countries had decided to return, whereas a small majority of those who had migrated alone to transit countries had decided not to return. More of those who had not migrated alone to destination countries had decided not to return than those who had decided to return, whereas it was the opposite in transit countries.

\section{Social factors}

Factors broadly categorised as 'social factors' were cited third most often among all the categories of factors identified in the model in Figure 10.1. By far the most important was a desire to rejoin family members at home, cited 57 times. As a single factor, this is the second most cited across the entire study, following the difficulty of finding work under the 'conditions 
in destination country' category. Here is a strong reminder that migration, and return migration, are as much social processes as they are economic and political processes.

Another social factor was changes in family circumstances (cited 26 times). It is unclear whether this refers to changes in circumstances among family in the destination country or the origin country, but it seems more likely to be in the latter. Nostalgia about the origin country and its way of life was cited nine times.

Perhaps the most surprising results in this category were that problems of integration and the shame of return ranked at the bottom of the variables. Many of the challenges of integration, for example to do with legal status and finding a job, are covered elsewhere in the survey and data. However, the specific factor of 'integration' could have been expected to figure more highly here.

Another way that social factors intersect with the return decision-making process is where other family members are involved in making the decision. Only 15 per cent of the respondents in this study had made the decision to migrate alone.

Reporting on their decisions after they had already returned home, respondents in origin countries named family members back at home as the most important influence in decision-making (38 per cent). Family members in the origin country were also most involved in the decision whether to return for those interviewed in destination countries (33 per cent) and transit countries (72 per cent). The particularly high response in this category for the latter group was presumably because so few had family members in the transit country to consult, whereas for those who had made it to their destination, family members there were also significantly involved in the decision. These findings illustrate the importance of policy interventions being considered not just at the individual migrant level, but also in the wider family context.

Finally, 13 per cent of respondents in transit and destination countries reported that both government authorities and the IOM were involved in the decision. Among respondents interviewed in destination countries, 22 per cent reported that government authorities had been involved in the decision, compared with only 5 per cent referencing the IOM. 


\section{Policy interventions}

It is not clear from this study if policy interventions play an important role in the decision whether to return. As an entire category, this was only the fourth most important of the five categories considered in the survey: cited by only about one fifth of the respondents. Equally, the variables considered here overlap and probably combine to influence the return decision. It is also worth reiterating that aspects of the return decision may be beyond direct policy intervention, for example regarding certain individual and social characteristics. The most important specific factor cited, 26 times, was the possibility to benefit from voluntary return programs, closely followed by compliance with the law to leave voluntarily.

\section{Information}

As well as having assistance programs in place, it is equally important that their intended beneficiaries know about them, understand who they apply to, what they offer, and under what circumstances. Migrants' knowledge about immigration policy in particular may often be subject to rumour and speculation. To begin to explore whether or not there is an information gap around assistance for return, respondents in origin and destination countries were asked what they knew about assistance programs and how they knew about them.

Across all four destination countries surveyed, 47 respondents had heard of assistance programs and only seven had not. It is somewhat surprising that any respondents had not come across these programs, as they were identified by the IOM, other return service agencies, or the government.

It is worth separately considering information dissemination in transit countries-a significant gap in existing research that this study can at least start to fill. In the transit countries, 45 respondents ( 75 per cent) knew something about return programs. Of these, 14 reported receiving the information from friends and family in the transit country; eight from the IOM; and the remainder from government authorities, a nongovernmental organisation (NGO), friends or family in a destination country, and friends or family in the origin country, in that order. 


\section{Conclusions}

Based on the model of return decision-making presented above, this section has drawn on data from respondents across the origin, transit and destination countries to try to understand the decision to return. Overall respondents ranked the five main categories of factors influencing the return decision as follows: by far most important were conditions in the country of destination, followed in order by individual factors, social factors, policy interventions and lastly conditions in the origin country. As discussed, this ranking is striking and in contrast to most other studies on return, in particular the positions of the final two categories.

Within these broad categories, the following specific variables were found to be most significant for the respondents in making their decisions: the difficulty of finding employment/no right to work; tired of living as an undocumented migrant; a desire to reunify with family at home; the opportunity to benefit from voluntary return programs; and job prospects at home.

Discerning policy implications from this analysis is challenging, not just because of the limitations of the methodology, but also because in reality the categories and variables distinguished here intersect and influence each other. Even though it may not be possible to highlight specific policy interventions, a number of wider policy implications emerge. First, the results suggest that neither 'sticks' nor 'carrots' alone work as policy interventions, and instead a judicious mix may be most effective. Second, there may be certain aspects of the return process that are largely beyond the influence of policy interventions, for example some of the social and cultural factors that may influence attitudes towards return and towards women. Finally, there is a reality check: assisted voluntary returnrelated policy interventions were not considered by most participants as a fundamental reason for their decision, and some said they did not even know about return programs and other assistance programs. 


\section{Defining and measuring sustainable return}

Drawing on an extensive literature review and consolidating key elements of various existing definitions, this study defines 'sustainable return' as when: 'The individual has reintegrated into the economic, social and cultural processes of the country of origin and feels that they are in an environment of safety and security upon return.'

This definition assumes that reintegration is a necessary precondition for meaningful sustainable return. It adopts a comprehensive perspective on reintegration across the dimensions of economic, sociocultural and political-security processes. This definition also highlights that the returnee must perceive they are in conditions of safety and security upon return (Black \& Gent, 2006).

According to this definition, sustainable return is achieved by: economic reintegration whereby an individual is able to sustain a livelihood and is not in a situation of economic vulnerability; social and cultural reintegration whereby the returnee is actively incorporated into the receiving society, for example at the local community level; and political-security reintegration whereby the returnee feels they have access to safety and justice upon return.

\section{Measuring sustainable return}

Using the definition and building on the measures established above, a return and reintegration index was created, combining the three dimensions of economic, sociocultural and safety/security criteria. As return and reintegration cannot be measured by one variable, an index is useful because it allows all the variables of interest to be combined to create a single measure.

The methodology used to develop the index follows that developed by Roelen and Gassman (2012)—based on work by Alkire and Santos (2010) and Alkire and Foster (2011) — to create a multidimensional child wellbeing index. The methodology consists of three simple steps and is replicable for the case of developing a multidimensional return and reintegration index. 
The three steps were:

- First a threshold was identified for each return and reintegration measure detailed above to assess if each returnee was reintegrated according to that variable. For example, on the measure 'employment', an individual was assessed as reintegrated if they were employed. Individual variable reintegration rates were then determined by counting the number of returnees who met the threshold requirement. This is a basic measure-for example it cannot gauge how long the returnee has been employed or the conditions of employment-but it provides a benchmark for understanding sustainability.

- Second, return and reintegration rates were determined for each dimension. The dimension 'reintegration' rates reflect the number of returnees who have achieved a sufficient level of reintegration across the dimension variables. Each variable was given an equal weight within the dimension. A returnee was considered reintegrated if the weighted indicator for the dimension was equal to or above 0.6 . This means that returnees had to meet a level of reintegration of at least three of the five variables in each dimension to be considered reintegrated. There are a number of assumptions in this step, regarding the weighting of variables and the 'cut-off' point for reintegration, which can be adjusted for further research.

- The third step was to create an overall return and reintegration index by aggregating the reintegration rates across the three dimensions. Each dimension was equally rated at one third of the total index. An individual was therefore considered to be reintegrated if they exceed the 60 per cent threshold across all three dimensions. Once again these arbitrary weightings and thresholds may be adjusted as necessary in future.

\section{Applying the return and reintegration index}

In the economic dimension of the return and reintegration index, 56 per cent of returns in the sample may be considered reintegrated in three out of five of the economic dimension indicators. Within this dimension, returnees were most vulnerable on the number of income sources in the household, as 35 per cent of returnees' households did not have more than one income source. Seventy per cent of returnees were employed, and this does include self-employment or part-time employment. Fifty-seven per cent of returnees currently had no debt. Of the 43 per cent of returnees 
who were currently in debt, 45 per cent had incurred the debt for their original migration. Costs of migration were cited as high as USD12,000, which is generally a much larger sum than return allowances offered. Similarly, 57 per cent of returnees currently owned land or their house. Finally, in terms of self-perception, 53 per cent of returnees perceived that they were currently struggling economically.

On the sociocultural dimension, 64 per cent of returnees were reintegrated. Within this dimension, returnees were most likely to participate in local events ( 79 per cent), but least likely to be a member in an organisation (21 per cent). Organisations in the survey included informal groups such as funeral or savings associations, which were quite common in several of the study countries, suggesting that the returnees had low levels of participation relative to the rest of the population. The majority of returnees identified themselves as having networks they could rely on for support (69.7 per cent) and having transnational networks (66.9 per cent). It is concerning that 41 per cent of returnees expressed that they were generally dissatisfied or very dissatisfied with their life in the past month.

Overall, returnees showed the highest levels of reintegration in the safety and security dimension, at 71 per cent. The majority of returnees reported feeling safe in their home (79.2 per cent) and in their community (69 per cent). Further, the majority had not experienced personal harassment since return (78.6 per cent) and felt they could access justice if their rights were violated ( 60.8 per cent).

On the whole, 37 per cent of returnees were reintegrated based on the index. There were significant variations in the degree of reintegration across the eight origin countries covered by this study. Returnees to Vietnam and Pakistan were more likely to be reintegrated. Returnees to Vietnam in this study had all returned from the UK and were a particular migrant group: the group interviewed from Vietnam tended to be better off economically compared with others in their local communities. In Pakistan, it appears that the reintegration assistance was meaningful in establishing employment in that country.

Returnees to Iraq were the least likely to be reintegrated on return. Afghanistan, Ethiopia and Sri Lanka also had very low percentages of returnees who were reintegrated. Similarly to Iraq, Afghans reported low levels of reintegration in the safety and security dimension, which 
is unsurprising given the current instability in Afghanistan. Ethiopians, Bangladeshis and Sri Lankans reported the lowest levels of economic reintegration.

\section{Conclusions}

This section has provided the basis of the analytical framework for measuring sustainable return through the return and reintegration index. The index highlights the multidimensional nature of reintegration and the importance of the three dimensions of economic reintegration, sociocultural reintegration, and safety/security. The interplay between these dimensions determines if an individual is reintegrated or not. It is evident that participants in the different origin countries had varying levels of reintegration, with returnees to Iraq being the least likely to be reintegrated and returnees to Vietnam and Pakistan the most likely to be reintegrated.

\section{Promoting reintegration and sustainable return}

This section explores the factors that influence sustainable return, drawing on the return and reintegration index presented above. Building from the literature review, the following categories of factors will be examined:

- individual factors

- the migration cycle, including experiences prior to migration and in the destination country

- structural factors during return including the community of return and attitudes from locals

- the role of assisted voluntary return programming.

It is important to note that these factors may overlap, and separating them out into categories is, to an extent, artificial. At the same time, this separation is helpful for analysis, and potentially also for targeting policy interventions to promote reintegration and sustainable return. 


\section{Individual factors}

The literature review found no systemic evidence on the impact of individual factors such as age, sex and education levels on reintegration and sustainable return. However, in one study comparing Bosnia and Kosovo, it was found that young men were more likely to be able to find employment upon return (Black et al., 2004).

Similarly, in this study's sample there was no significant relationship either between age or sex and reintegration, as measured by the aggregate return and reintegration index. Individuals in their 30 s were the most likely to be reintegrated, and individuals over 50 or between 17 and 29 years of age were the least likely to be reintegrated. Although the total numbers are small, it may also be noteworthy that only 24 per cent of female returnees were reintegrated, compared with 40 per cent of male returnees (still less than half). This is in line with the conclusions of other studies that reintegration is a gendered process, often more difficult for women than men (Wong, 2013).

A noteworthy relationship was found between education and reintegration. Those with no primary education, or only with primary education, were reintegrated less than those with a secondary education who, in turn, were reintegrated less than those with a tertiary education. On one hand, those educated to a tertiary level may be expected to be more likely to find employment upon return. On the other hand, however, still only 52 per cent of those with tertiary education were reintegrated, and it may be that the most educated are the most likely not to find work commensurate with their skills and training.

\section{Experiences prior to migration}

As uncovered by the literature review, an individual's situation prior to their migration can have a significant impact on their potential to be reintegrated upon return. In general, for example, earlier studies have indicated that those who are well off prior to migration (for example, in terms of personal security, employment and financial resources) have a higher likelihood of also being well off on return.

In contrast, this study's findings indicated no significant relationship between reintegration and either employment prior to migration or an individual's self-perception of their standard of living prior to migration. For both those who were and those who were not working prior to 
migration, around 40 per cent were reintegrated and 60 per cent were not. In regard to standard of living prior to migration, however, a higher percentage of those who were comfortable prior to migration were reintegrated (46 per cent), compared with those who reported struggling prior to migration (27.9 per cent).

The study found instead that social and political-security experiences prior to migration were significant factors in determining likelihood of reintegration. Twenty-two per cent of participants stated that they did not have a sense of belonging to the community prior to migration. This group was found to be significantly less likely to be reintegrated, compared with those who did have a sense of belonging prior to migration ( 42 per cent).

It is also not surprising that individuals who reported experiencing threats to their personal security prior to their migration were also significantly less likely to be reintegrated (27.1 per cent), compared with those who had not apparently experienced threats prior to migration (47.9 per cent). Also, unsurprisingly, those who had reported experiencing threats prior to migration were particularly less reintegrated on the safety-security dimension of the return and reintegration index, at 60 per cent reintegrated, compared with 86 per cent of those who had not cited experienced threats prior to migration.

\section{Experiences in the destination country}

Participants had returned from a total of 25 different countries of destination; the four most common countries were Norway (32), UK (27), Greece (25) and Belgium (14). There is a clustering effect of return from Greece being primarily to Pakistan and Bangladesh, and 56 per cent of returnees from the UK went home to Vietnam.

According to the data in this study, returnees from the UK were significantly more likely to be reintegrated (60.9 per cent), whereas returnees from Belgium were significantly less likely to be reintegrated (21.4 per cent). The situation of the UK, however, must be interpreted with caution. As indicated, all returnees in the sample in Vietnam had returned from the UK, and this represented a highly specific migration stream. When excluding Vietnam from the sample, there were 12 remaining participants who returned from the UK. Only one of these 
participants was reintegrated upon return. For all the other destination countries, around one third of returnees were reintegrated according to the return and reintegration index. This could not be defined as success.

The study also examined the relationship between the living situation in the destination country, employment, time spent in the destination country and reintegration. The living situation on arrival comparison indicates that individuals in asylum reception centres were significantly less likely to be reintegrated. Only 21 per cent of this group could be described as reintegrated, according to the index. Although the sample size for detention centres is very small, it is striking that those respondents who had spent time in asylum centres were even less likely to be reintegrated than those in detention centres.

The majority of returnees were not legally entitled to work while in the destination country; however, 41 per cent had worked informally at some point during their stay. On the whole, there was no clear relationship between working or not working in the destination country and reintegration. Interestingly, those who had worked informally were better reintegrated than those who had worked legally ( 47.2 per cent compared to 28.6 per cent).

Finally, it might be expected that reintegration would become more unlikely when migrants had been away for a longer period of time. Indeed, participants who had been abroad for over 10 years were the least likely to be reintegrated, although this was not statistically significant. There was, however, little variation in the correlation between duration abroad and reintegration for other time periods_-ranging between 33 and 47 per cent for all other time periods. A recent study has argued that duration abroad itself is not significant in returnee reintegration; rather, it is the experiences abroad that matter more (Kuschminder, 2014).

\section{Community of return}

Within the broad range of conditions in the country of origin, the community level was an especially important factor in reintegration. Individuals who returned to the same community where they lived before they left were significantly more likely to be reintegrated, compared with individuals who returned to a different community than the one they left: 44.9 per cent compared with 19.5 per cent. This has potentially important implications for policy, suggesting a correlation between community of return and reintegration, and highlighting the risks of return where 
access to the community of origin is not yet feasible. There are at least two potential reasons to explain this. First, people only return to the same community when they do not feel their safety and security will be violated in that community, therefore already suggesting a higher level of reintegration within this dimension. Second, people return to the same community when they have existing networks or support services within that community, which would also suggest higher levels of reintegration in the sociocultural dimension. In addition, individuals who returned to an urban community were more likely to be reintegrated than those who returned to a rural community.

\section{Conclusions}

This section has examined the relationship between different variables pertaining to the circumstances and experiences of the returnees and their migration cycle, and reintegration as measured by the return and reintegration index. Several factors were assessed to have a significant relationship with reintegration. These included having a sense of belonging in the community prior to migration, the reason for migration, the country of destination, residing in an asylum reception centre and returning or not returning to the same community on return.

\section{Policy implications}

In drawing initial policy implications, a number of reservations are worth flagging: The first concerns the research topic itself. The decision to return, reintegration, and the sustainability of return all often depend on highly individual characteristics and experiences, many of which defy accurate measurement or prediction. In part, therefore, the value of this research has been to identify areas where policy is unlikely to make a difference. At the same time, however, it does allow at least for preliminary conclusions about where policy interventions can be effective.

A second reservation concerns the research process. While every effort was made to ensure a degree of trust between interviewer and respondent, there can be no guarantee of the accuracy of the responses provided by respondents. In part, this reflects the sensitive and sometimes vulnerable situation in which some respondents found themselves. It also reflects the nature of the research, which in some cases depended on participants' 
recall up to a year after making certain decisions and taking actions as well as requiring responses to hypothetical questions, from which final actions may diverge significantly.

A related consideration concerns access to evidence and data. Various aspects of return programs have been monitored and evaluated in several of the study countries, including by governments and relevant organisations. However, this information was not always easily accessible, and neither was it collated in a single location. In several origin countries the tracking of returnees is not systematic or thorough enough to answer important questions regarding reintegration and sustainable return. This has implications for the management, analysis, and publication of data and evidence by government authorities and international organisations.

Fourth, a key gap in this study is determining the role of assisted voluntary return and reintegration packages in the overall reintegration process. All participants in this study had received reintegration assistance, and therefore the study was not able to compare their experiences with those of other assisted voluntary returnees who did not receive reintegration assistance. Neither could it systematically compare the relevance or differential outcomes of different types of assistance packages. This has direct implications for program management and assisted voluntary return policy design, and should be explored in further research.

A final reservation concerns the wider applicability of these findings. None can be considered representative of the nationality groups or countries surveyed, let alone of migrants or returnees more generally. The purpose of focusing on a semi-structured interview approach was therefore to identify and explore relevant issues rather than provide firm conclusions.

Bearing in mind these reservations, while also recognising the uniquely comprehensive and comparative nature of the study, the findings of the study have implications for policy in three main areas: influencing the decision to return, measuring sustainability, and promoting sustainable return and reintegration.

\section{Influencing the decision to return}

- Conditions in their origin countries were generally not an important influence on the respondents' decisions on whether to return. This is likely to reflect the fact that nearly half of respondents migrated for broadly economic reasons, and would likely differ among asylum seekers and refugees. 
- Conditions in destination countries may strongly influence the decision to return. For many respondents, an inability to work and insecure legal status in particular were important incentives to return, although rarely in isolation from other individual and social factors.

- Other key factors influencing the decision to return are largely beyond the scope of direct policy interventions. For example, the desire to reunite with family members at home, or a change of family circumstances there, were also important factors in the return decision. Family members were also often involved in the decision-making process.

- Policy interventions are not considered a major influence on the decision whether to return.

- Enabling policy interventions can influence the decision to return as much as restrictive policies. For many respondents, the opportunity to benefit from voluntary return programs, and the chance to wind up their affairs before departure, facilitated their return decision.

- More could be done to disseminate information on return programs, especially in transit countries. In contrast to destination countries, where most respondents knew about return programs and from multiple sources, in transit countries almost half had not even heard of return programs. Equally, it is important not to raise the expectations of migrants, many of whom may not be eligible for limited return assistance programs.

- There is a fine line between facilitating return and encouraging it. Any policy intervention in this area should be designed to allow potential returnees to make their own decisions, rather than encouraging them towards any particular option.

\section{Measuring sustainability}

- Measuring sustainability depends on how it is defined. The definition proposed in this study is that "The individual has reintegrated into the economic, social and cultural processes of the country of origin and feels that they are in an environment of safety and security upon return'.

- It is possible to develop an index for measuring reintegration. The index developed in this study distinguishes economic, sociocultural, and political-security dimensions, and sets reintegration thresholds across each to gauge individual reintegration rates. The variables and the thresholds can be adjusted for future studies. 
- To measure sustainability for individual returnees, it is important to set up an adequate sample frame at an early stage of a return program. It was not possible in any of the origin countries to obtain a representative sample of returnees from which to gain a generalised view of the sustainability of return for individuals.

- A system to measure reintegration and the sustainability of return could be put in place as part of any future voluntary assisted return program.

- Ongoing monitoring of sustainability is possible, but involves tradeoffs in terms of costs. In particular, the in-depth interviews that would be required to properly gauge sustainability take time, and are challenging from a logistical perspective.

- Remigration is not a valid proxy for measuring sustainability.

\section{Promoting sustainable return and reintegration}

- Many of the factors influencing the sustainability of return appear beyond the influence of direct policy intervention. These include premigration experiences such as level of education and social belonging, and individual characteristic such as sex.

- Living conditions in the destination country are significantly correlated with sustainable return and reintegration. This was particularly the case in this sample for returnees who had spent significant periods in asylum or detention centres, very few of whom were subsequently reintegrated.

- The ability to work in the country of destination does not clearly correlate with sustainable return or reintegration.

- The ability to return to the community in which respondents lived before migration promoted sustainable return and reintegration. This was particularly the case where the community was in an urban area.

- The reason for initial migration significantly correlates with reintegration. Individuals who migrated for political-security reasons were less likely to be reintegrated than those who migrated for economic reasons. This suggests that, although migration motivations are frequently mixed, the distinctions are still important when examining the reintegration process.

- The factors that influence return may also impact on its sustainability and reintegration, but sometimes in opposing directions. In particular, a negative decision on asylum was a strong determinant for return, but also a strong indicator for a lack of reintegration after return. 


\section{Reference list}

Alkire, S., \& Foster, J. (2011). Counting and multidimensional poverty measurement. Journal of Public Economics 95(7-8), 476-97. doi.org/ 10.1016/j.jpubeco.2010.11.006

Alkire, S., \& Santos, M. E. (2010). Acute multidimensional poverty: A new index for developing countries. Oxford Poverty and Human Development Initiative working paper No. 38. Oxford: Department of International Development, University of Oxford.

Black, R., \& Gent, S. (2006). Sustainable return in post-conflict contexts. International Migration, 44(3), 15-38. doi.org/10.1111/j.1468-2435. 2006.00370.x

Black, R., Koser, K., Monk, K., Atfield, G., D’Onofrio, L., \& Tiemoko, R. (2004). Understanding voluntary return. Home Office Report 50/04. London: Home Office.

Koser, K., \& Kuschminder, K. (2015). Comparative research on the assisted voluntary return and reintegration of migrants. Geneva: Intermational Organization for Migration. Retrieved from www.iom.int/files/live/ sites/iom/files/What-We-Do/docs/AVRR-Research-final.pdf.

Kuschminder, K. (2014). Female return migration and reintegration strategies in Ethiopia (unpublished $\mathrm{PhD}$ dissertation). Maastricht Graduate School of Governance, Germany.

Paasche, E. (2014). Why assisted return programmes must be evaluated. Insights from the project 'Possibilities and realities of return migration'. Peace Research Institute, policy brief No. 5. Oslo: Peace Research Institute.

Roelen, K., \& Gassman, F. (2012). Child well-being in Kazakhstan. Atana, Kazakhstan: United Nations Children's Fund.

Wong, M. (2013). Navigating return: The gendered geographies of skilled return migration to Ghana. Global Networks, 14(4), 438-57. doi.org/ 10.1111/glob.12041 
This text is taken from A Long Way to Go: Irregular Migration Patterns, Processes, Drivers and Decision-making, edited by Marie McAuliffe and Khalid Koser, published 2017 by ANU Press, The Australian National University, Canberra, Australia.

dx.doi.org/10.22459/LWG.12.2017.10 